\title{
The MPI-Mainz UV/VIS Spectral Atlas of Gaseous Molecules of Atmospheric Interest
}

\author{
H. Keller-Rudek ${ }^{1}$, G. K. Moortgat ${ }^{2}$, R. Sander ${ }^{2}$, and R. Sörensen ${ }^{1}$ \\ ${ }^{1}$ Satellite Group, Max-Planck Institute of Chemistry, P.O. Box 3060, 55020 Mainz, Germany \\ ${ }^{2}$ Air Chemistry Department, Max-Planck Institute of Chemistry, P.O. Box 3060, 55020 Mainz, Germany \\ Correspondence to: H. Keller-Rudek (hannelore.keller-rudek@mpic.de) and R. Sander (rolf.sander@mpic.de)
}

Received: 7 May 2013 - Published in Earth Syst. Sci. Data Discuss.: 7 August 2013

Revised: 22 October 2013 - Accepted: 25 October 2013 - Published: 3 December 2013

\begin{abstract}
We present the MPI-Mainz UV/VIS Spectral Atlas of Gaseous Molecules, which is a large collection of absorption cross sections and quantum yields in the ultraviolet and visible (UV/VIS) wavelength region for gaseous molecules and radicals primarily of atmospheric interest. The data files contain results of individual measurements, covering research of almost a whole century. To compare and visualize the data sets, multicoloured graphical representations have been created. The MPI-Mainz UV/VIS Spectral Atlas is available on the Internet at http://www.uv-vis-spectral-atlas-mainz.org. It now appears with improved browse and search options, based on new database software. In addition to the Web pages, which are continuously updated, a frozen version of the data is available under the doi:10.5281/zenodo.6951.
\end{abstract}

\section{Introduction}

The MPI-Mainz UV/VIS Spectral Atlas of Gaseous Molecules (MPI - Max-Planck Institute for Chemistry; UV/VIS - ultraviolet and visible) is a large collection of cross sections and quantum yields for gaseous molecules and radicals, primarily relevant to atmospheric research. The project started in the early nineteen eighties when such data became increasingly important for the precise determination of kinetic and photochemical data of many elementary reactions. At our laboratory, we started with the collection of papers related to the determination of absorption cross sections and quantum yields, and proceeded to produce a digital database of these parameters. In cooperation with the Forschungszentrum Jülich and the Deutsche Fernerkundungsdatenzentrum, a first collection of absorption spectra was published in two volumes for 80 inorganic and 120 organic molecules (Röth et al., 1997a, b), together with the corresponding numerical data on a CD-ROM (Nölle et al., 1998).

The collection of spectral data was extended when one of the authors (G. K. Moortgat) joined the JPL-NASA Evaluation Panel "Chemical Kinetic and Photochemical Data for Use in the Atmosphere" in 1998. For the evaluation of the photochemical parameters, it became evident that an up-todate collection was needed in order to recommend absorption cross sections and quantum yields for many species of atmospheric relevance.

An advanced collection together with a set of numerical data was created, subdivided into molecular categories and further augmented with multicoloured graphical representations. The initial MPI-Mainz UV/VIS Spectral Atlas of Gaseous Molecules was first presented at the European Geosciences Union (EGU) meeting in 2003, and made available to the scientific community by interactive access through the Web in 2005. This first online MPI-Mainz Spectral Atlas consisted of a collection of nearly 4000 numerical data files and about 1300 graphical representations for about 600 species. Although the database and the Web pages have been continuously updated since 2005 , it became evident and necessary to update and improve the software, data handling and search options to create a more modern up-to-date, easy-tohandle user interface.

The current spectral atlas is now available at http://www. uv-vis-spectral-atlas-mainz.org. As of October 2013, the database contains more than 5500 cross section data files for more than 900 species, about 150 quantum yield data files 
for 30 reactions, about 1600 references, and more than 2400 graphical representations. This paper describes the latest development of the MPI-Mainz-UV/VIS Spectral Atlas. It is structured as follows: Sect. 2 describes the scientific background of the presented data, whereas Sects. 3 and 4 present the cross sections and the quantum yields in the database, respectively. Finally, in Sect. 5 we show some technical details about the current implementation.

\section{Scientific background}

The photolysis rates of gaseous trace species in the atmosphere are important parameters of profound interest to all atmospheric scientists. This is especially true for modelling atmospheric chemistry, as most chemical reactions are directly or indirectly driven by the Sun's radiation. Photolysis rates not only depend on the intensity of the actinic flux, but also on the photochemical and photophysical properties of the absorbing molecules. Photodissociation rate coefficients are governed by the wavelength-dependent absorption cross section $\sigma$ of the absorbing species and the quantum yield $\phi$ of the photolysis process.

The absorption cross section $\sigma$ is defined by the BeerLambert law describing the attenuation of light by a homogeneous absorbing system:

$\ln \left(\frac{I}{I_{0}}\right)=-\sigma n d$,

where $I_{0}$ and $I$ are the intensity of incident and transmitted monochromatic light, $n$ is the number concentration of the absorber (in molecule $\mathrm{cm}^{-3}$ ),$d$ is the absorption path length (in $\mathrm{cm}$ ), and $\sigma$ is the absorption cross section. Usually, the unit $\mathrm{cm}^{2}$ molecule ${ }^{-1}$ is used for $\sigma$. However, sometimes megabarn $\left(1 \mathrm{Mb}=10^{-18} \mathrm{~cm}^{2}\right.$ molecule $\left.{ }^{-1}\right)$ is used in the literature.

A similar quantity is the molar extinction coefficient $\varepsilon$ (also called molar absorption coefficient or molar absorptivity), which uses the molar concentration $c$ (in $\mathrm{mol} \mathrm{L}^{-1}$ ) of the absorber instead of the number concentration:

$\ln \left(\frac{I}{I_{0}}\right)=-\varepsilon c d$.

Molar extinction coefficients $\varepsilon$ are given in $\mathrm{L} \mathrm{mol}^{-1} \mathrm{~cm}^{-1}$. Sometimes the symbol $\alpha$ is used instead of $\varepsilon$.

Some (mostly older) original papers use absorption coefficients $k$ (unit $\mathrm{cm}^{-1}$ ) with a definition based on the molar volume $V_{\mathrm{m}}$ of an ideal gas $\left(\mathrm{cm}^{3} \mathrm{~mol}^{-1}\right)$ at some reference state and the Avogadro constant $N_{\mathrm{A}}=6.022 \times$ $10^{23}$ molecule $\mathrm{mol}^{-1}$ :

$\ln \left(\frac{I}{I_{0}}\right)=-k \frac{V_{\mathrm{m}}}{N_{\mathrm{A}}} n d$.

Typical choices for the reference state are a temperature of $273 \mathrm{~K}$ or $298 \mathrm{~K}$ and a pressure of either $1 \mathrm{~atm}$ or 1 Torr. Without a clearly defined reference state, $k$ is ambiguous.
Instead of the natural logarithm, the decadic logarithm can be used for all these equations. This results in a conversion factor of $\ln 10$ :

$\log _{10}\left(\frac{I}{I_{0}}\right)=\ln \left(\frac{I}{I_{0}}\right) / \ln 10$.

Unfortunately, molar extinction coefficients ( $\varepsilon$ or $\alpha$ ) are often used in the literature without referring to base 10 or base $e$.

The quantum yield $\phi$ is the probability that a particular photochemical process will occur following the absorption of a photon by the molecule.

Both $\sigma$ and $\phi$ can depend on wavelength $\lambda$, temperature, and pressure. Thus, knowing their values at atmospheric conditions is essential. In addition, the experimental determination of kinetic and photochemical parameters of many elementary reactions requires the precise knowledge of the absorption cross sections of many species.

\section{Absorption cross sections}

\subsection{Coverage}

The collection includes results from measurements performed during the last ten decades, from the earliest measurements of absorption cross sections for gaseous chlorine by von Halban and Siedentopf (1922) or measurements for hydrogen peroxide by Urey et al. (1929), up to the most recent high-resolution absorption spectra for species such as formaldehyde, hydroxycarbonyls, fluorinated alcohols, aldehydes, and alkenes, as well as limonene (Smialek et al., 2012; Es-sebbar et al., 2013).

The data are divided into categories and subcategories, a complete list of the categories is presented in Table 1. The largest category is that of the "halogeno-alkanes + radicals", which shows the relevance of these species in atmospheric research with seven subcategories "bromoalkanes", "chloroalkanes", "fluoroalkanes", "freons- $\mathrm{CFC}(\mathrm{C}, \mathrm{F}, \mathrm{Cl})$ ", "freons-HCFC(C,H,F,Cl)", "halons $(\mathrm{C}, \mathrm{H}, \mathrm{F}, \mathrm{Cl}, \mathrm{Br})$ ", and "iodoalkanes $(\mathrm{C}, \mathrm{H}, \mathrm{F}, \mathrm{Cl}, \mathrm{Br}, \mathrm{I})$ ". An important and mentionable category is "ozone", showing more than 200 data files and 36 plots. The data result from ozone studies over 80 years, beginning with the earliest measurements in the Hartley-Huggins band by a Chinese team in the 1930s (Ny and Choong, 1932, 1933a, b), measurements in the Chappuis and Hartley-Huggins bands by French teams in the late 1940s (Vassy and Vassy, 1948) and early 1950s (Vigroux, 1950), numerous high-resolution studies in the UV and visible regions in the nineteen-eighties until the early 2000s, and up to measurements in the range of the very weak Huggins-Chappuis minimum (using broadband cavity enhanced absorption spectrometry) during recent years.

Also important are the categories "oxygen" (containing $\mathrm{O}_{2}$ and $\mathrm{O}_{4}$ ) with studies in the ultraviolet (UV), vacuum ultraviolet (VUV) and extreme ultraviolet (EUV) carried out over the last seventy years, and "nitrogen oxides" of which $\mathrm{NO}_{2}$ 
Table 1. Classification of the species into categories and subcategories.

\begin{tabular}{|c|c|c|c|c|}
\hline Category & Subcategories & Species & Data files & Plots \\
\hline Alcohols & & 26 & 65 & 71 \\
\hline Alkali compounds & $\mathrm{Li}, \mathrm{K}, \mathrm{Rb}, \mathrm{Cs}$ compounds / Na compounds & 23 & 39 & 11 \\
\hline Alkanes+alkyl radicals & Alkanes / Alkyl radicals & 27 & 128 & 48 \\
\hline Alkanes+radicals with $\mathrm{O}$ & & 5 & 5 & 6 \\
\hline Alkenes, dienes+radicals & Alkene radicals / Alkenes / Dienes & 37 & 157 & 103 \\
\hline Alkynes,polyynes+radicals & Alkyne radicals / Alkynes / Polyynes & 11 & 87 & 36 \\
\hline Aromatic compounds & $\begin{array}{l}\text { Aldehydes / Alkyl-,vinylbenzenes / Aromatic Radicals / Benzene / } \\
\text { Benzene oxide-oxepin,toluene oxide-methyloxepin / Halogenated } \\
\text { benzenes / Heterocyclic / Ketones / Nitro compounds / Phenol, } \\
\text { alkylphenols }\end{array}$ & 142 & 371 & 386 \\
\hline Boron compounds & & 7 & 11 & 14 \\
\hline Carbon-oxides & & 3 & 94 & 27 \\
\hline Ethers+alkyl radicals & Cyclic ethers / Linear and branched ethers & 28 & 49 & 52 \\
\hline Halogenated N-compounds(inorg) & & 19 & 125 & 44 \\
\hline Halogeno-alkanes+radicals & $\begin{array}{l}\text { Bromoalkanes / Chloroalkanes / Fluoroalkanes / Freons- } \\
\mathrm{CFC}(\mathrm{C}, \mathrm{F}, \mathrm{Cl}) / \text { Freons-HCFC(C,H,F,Cl) / Halons }(\mathrm{C}, \mathrm{H}, \mathrm{F}, \mathrm{Cl}, \mathrm{Br}) / \\
\text { Iodoalkanes }(\mathrm{C}, \mathrm{H}, \mathrm{F}, \mathrm{Cl}, \mathrm{Br}, \mathrm{I})\end{array}$ & 109 & 1041 & 337 \\
\hline Halogeno-alkenes+radicals & $\begin{array}{l}\text { Bromoalkenes / Bromofluoroalkenes / Chloroalkenes / Chloroflu- } \\
\text { oroalkenes / Fluoroalkenes / Iodoalkenes }\end{array}$ & 35 & 75 & 63 \\
\hline Halogeno-alkynes+radicals & & 2 & 2 & 8 \\
\hline Halogen oxides & $\mathrm{Br}$ oxides / $\mathrm{Cl}$ oxides / $\mathrm{F}$ oxides / I oxides / Mixed oxides & 23 & 317 & 61 \\
\hline Halogens + mixed halogens & & 9 & 139 & 35 \\
\hline Hydrogen halides & & 6 & 62 & 25 \\
\hline Hydrogen+water & & 5 & 93 & 46 \\
\hline Hypohalides & & 7 & 35 & 13 \\
\hline Nitrogen+compounds $(\mathrm{N}, \mathrm{H}, \mathrm{O})$ & & 12 & 170 & 68 \\
\hline Nitrogen oxides & & 7 & 392 & 56 \\
\hline Organics (acids) & & 20 & 65 & 50 \\
\hline Organics (carbonyls) & $\begin{array}{l}\text { Aldehydes(aliphatic) / Amides / Bicarbonyls / Carbonyl } \\
\text { oxides / Cyanocarbonyls / Esters / Halogenated aldehydes / } \\
\text { Ketones,ketenes / Organic radicals }\end{array}$ & 121 & 674 & 330 \\
\hline Organics (N-compounds) & $\begin{array}{l}\text { Amines / Azides / Azoalkanes / Carbazoles / Cyanogen halides / } \\
\text { Dinitrates / Nitrates / Nitriles / Nitrites / Nitroketones / Nitro-, } \\
\text { nitrosoalkanes / Nitrooxy-alcohols / Peroxynitrates }\end{array}$ & 71 & 247 & 154 \\
\hline Oxygen & & 2 & 203 & 36 \\
\hline Ozone & & 1 & 211 & 36 \\
\hline Peroxides & $\begin{array}{l}\text { Alkyl peroxides / Halogenated peroxides / Hydrogen peroxide } \\
\mathrm{H} 2 \mathrm{O} 2 \text { / Hydroxyalkylperoxides / Ketohydroperoxides }\end{array}$ & 14 & 62 & 33 \\
\hline Peroxy radicals & $\begin{array}{l}\text { Acetonylperoxy / Acylperoxy / Alkylperoxy / Alkylperoxy+Br,I / } \\
\text { Alkylperoxy+Cl / Alkylperoxy+F / Alkylperoxy+F+Cl / Hy- } \\
\text { droperoxy } \mathrm{HO} 2 \text { and DO2 / Hydroxy-, methoxyalkylperoxy / Oth- } \\
\text { ers / Vinyl-,allylperoxy }\end{array}$ & 58 & 254 & 98 \\
\hline Phosphor compounds & & 14 & 22 & 29 \\
\hline Silicon compounds & & 16 & 25 & 46 \\
\hline Sulfur compounds & Inorganic S-compounds / Organic S-compounds & 53 & 288 & 131 \\
\hline Terpenes & & 3 & 3 & 6 \\
\hline Unclassified & & 11 & 11 & 10 \\
\hline
\end{tabular}


Table 2. Example for metadata associated with a cross section data set. The corresponding data file is shown in Table 3.

\begin{tabular}{|c|c|}
\hline \multicolumn{2}{|c|}{ Cross Sections / Halogen oxides / Br oxides / BrO / Cox(1982)_298K_300-375nm(5nm,int-c) } \\
\hline DATAFILE: & BrO_Cox(1982)_298K_300-375nm(5nm,int-c).txt \\
\hline NAME: & bromine monoxide \\
\hline FORMULA: & $\mathrm{BrO}$ \\
\hline AUTHOR(YEAR): & $\operatorname{Cox}(1982)$ \\
\hline $\mathrm{T}$ : & $298 \mathrm{~K}$ \\
\hline$\lambda:$ & $300-375 \mathrm{~nm}(5 \mathrm{~nm}$,int-c $)$ \\
\hline BIBLIOGRAPHY: & $\begin{array}{l}\text { R. A. Cox, D. W. Sheppard, and M. P. Stevens, "Absorption coefficients and kinetics of the BrO radical } \\
\text { using molecular modulation," J. Photochem., 19, 189-207 (1982) }\end{array}$ \\
\hline COMMENTS: & $\begin{array}{l}\text { 300-375 nm(int-c), i.e., averaged over spectral intervals of } 5 \mathrm{~nm} \text { at } 300-305,305-310, \ldots .370-375 \mathrm{~nm} \text {; } \\
\text { first column: center of interval }\end{array}$ \\
\hline
\end{tabular}

Table 3. As an example for a cross section data file, the contents of BrO_Cox(1982)_298K_300-375nm(5nm,int-c).txt is shown here. It belongs to the data set from Cox et al. (1982) shown in Table 2.

\begin{tabular}{ll}
\hline 302.5 & $2.00 \mathrm{e}-18$ \\
307.5 & $2.59 \mathrm{e}-18$ \\
312.5 & $4.54 \mathrm{e}-18$ \\
317.5 & $3.91 \mathrm{e}-18$ \\
322.5 & $6.00 \mathrm{e}-18$ \\
327.5 & $7.53 \mathrm{e}-18$ \\
332.5 & $6.28 \mathrm{e}-18$ \\
337.5 & $5.89 \mathrm{e}-18$ \\
342.5 & $5.15 \mathrm{e}-18$ \\
347.5 & $3.99 \mathrm{e}-18$ \\
352.5 & $2.28 \mathrm{e}-18$ \\
357.5 & $1.72 \mathrm{e}-18$ \\
362.5 & $1.61 \mathrm{e}-18$ \\
367.5 & $9.20 \mathrm{e}-19$ \\
372.5 & $5.10 \mathrm{e}-19$ \\
\hline
\end{tabular}

shows the greatest number of studies in the visible and UV region.

\subsection{File format and naming conventions}

Metadata associated with each data set (formula and name, category, reference, temperature, wavelength range, comments) is presented as shown in the example in Table 2. In addition, the database contains the CAS registry number ${ }^{1}$ and the InChIKey ${ }^{2}$ for most species. ASCII text files (*.txt) with two columns contain the numerical data (see Table 3 for an example). The first column gives the wavelength $\lambda$ (in $\mathrm{nm}$ ) (generally in air unless vacuum wavelengths are specified). The second column contains the absorption cross section $\sigma$ (in $\mathrm{cm}^{2}$ molecule ${ }^{-1}$ ). The "E notation" is chosen for the absorption cross sections in the data files, e.g. "1.5e-18" is to be read as $1.5 \times 10^{-18}$. In some cases, a third column shows the uncertainties of the measured values. Each data set refers to an individual measurement per species. The names of the data files consist of four parts, separated by the underscore character:

formula_author(year)_T_ $\lambda$.txt

where $T$ denotes the temperature and $\lambda$ the wavelength range. Here, author is the name of the first author. If there are two authors, both names are concatenated without a space:

03_ClyneCoxon(1968)_294K_250nm.txt

The file names do not contain non-ASCII characters, thus some author names had to be modified, e.g. Jiménez $\rightarrow$ Jimenez, Limão-Vieira $\rightarrow$ Limao-Vieira, and Mössinger $\rightarrow$ Mossinger. Spaces in last names are omitted, e.g. Le Bras $\rightarrow$ LeBras and El Dib $\rightarrow$ ElDib. Hyphens in names are not modified:

C-C4F8_Limao-Vieira(2007)_298K_115-204nm.txt

In some cases, additional specifications are added in brackets after the wavelength:

OI0_Bloss(2001)_295K_516-572nm(1nm).txt

which indicates $1 \mathrm{~nm}$ intervals, or

03_JPL-2010(2011)_293-298K_121.6-827.

$5 \mathrm{~nm}(\mathrm{rec})$. txt

where ( $\mathrm{rec}$ ) indicates that the cited publication is a recommendation, not original laboratory work. There are several other specifications in brackets that are explained in the comments on the Web page.

\subsection{Units}

The absorption cross sections $\sigma$ in the database have consistently been converted to $\mathrm{cm}^{2}$ molecule ${ }^{-1}$ (base $e$ ) according to the Beer-Lambert law, as described in Eq. (1). The conversion factors that were used are listed in Table 4.

An exception is the collision-induced absorption spectrum of the oxygen dimer $\mathrm{O}_{4}$ where the Beer-Lambert law no longer holds. Here, the binary absorption cross sections are given in $\mathrm{cm}^{5}$ molecule ${ }^{-2}$.

\footnotetext{
${ }^{1}$ http://www.cas.org/content/chemical-substances/faqs

${ }^{2} \mathrm{http}: / /$ www.inchi-trust.org
} 
Table 4. Conversion factors from absorption coefficients $k$ and extinction coefficients $\varepsilon$ to absorption cross sections $\sigma$ in $\mathrm{cm}^{2} \mathrm{molecule}^{-1}$.

\begin{tabular}{lllll}
\hline Quantity (unit) & Log base & Reference state & Conversion formula* & Conversion factor \\
\hline absorption coefficient & base $e$ & $298 \mathrm{~K}, 1 \mathrm{~atm}$ & $V_{\mathrm{m}}(298 \mathrm{~K}, 1 \mathrm{~atm}) / N_{\mathrm{A}}$ & $4.06 \times 10^{-20} \mathrm{~cm}^{3} \mathrm{molecule}^{-1}$ \\
$k\left(\mathrm{~cm}^{-1}\right)$ & base $e$ & $273 \mathrm{~K}, 1 \mathrm{~atm}$ & $V_{\mathrm{m}}(273 \mathrm{~K}, 1 \mathrm{~atm}) / N_{\mathrm{A}}$ & $3.72 \times 10^{-20} \mathrm{~cm}^{3} \mathrm{molecule}^{-1}$ \\
& base 10 & $298 \mathrm{~K}, 1 \mathrm{~atm}$ & $\ln 10 \times V_{\mathrm{m}}(298 \mathrm{~K}, 1 \mathrm{~atm}) / N_{\mathrm{A}}$ & $9.35 \times 10^{-20} \mathrm{~cm}^{3} \mathrm{molecule}^{-1}$ \\
& base 10 & $273 \mathrm{~K}, 1 \mathrm{~atm}$ & $\ln 10 \times V_{\mathrm{m}}(273 \mathrm{~K}, 1 \mathrm{~atm}) / N_{\mathrm{A}}$ & $8.57 \times 10^{-20} \mathrm{~cm}^{3} \mathrm{molecule}^{-1}$ \\
& base 10 & $298 \mathrm{~K}, 1 \mathrm{Torr}$ & $\ln 10 \times V_{\mathrm{m}}(298 \mathrm{~K}, 1 \mathrm{Torr}) / N_{\mathrm{A}}$ & $7.11 \times 10^{-17} \mathrm{~cm}^{3} \mathrm{molecule}^{-1}$ \\
\hline extinction coefficient & base $e$ & & $f / N_{\mathrm{A}}$ & $1.66 \times 10^{-21} \mathrm{~cm}^{3} \mathrm{molecule}^{-1} \mathrm{~mol} \mathrm{~L}^{-1}$ \\
$\varepsilon\left(\mathrm{L} \mathrm{mol} \mathrm{mol}^{-1}\right)$ & base 10 & & $f \times \ln 10 / N_{\mathrm{A}}$ & $3.82 \times 10^{-21} \mathrm{~cm}^{3} \mathrm{molecule}^{-1} \mathrm{~mol} \mathrm{~L}^{-1}$ \\
\hline
\end{tabular}

${ }^{*}$ Here, $N_{\mathrm{A}}=6.022 \times 10^{23}$ molecule mol $^{-1}$ is the Avogadro constant, $\ln 10=2.303$ is the natural logarithm of $10, f=1000 \mathrm{~cm}^{3} \mathrm{~L}^{-1}$ is the factor converting from cubic centimetre to litre, and $V_{\mathrm{m}}$ is the molar volume of an ideal gas at the reference state, i.e. $V_{\mathrm{m}}(273 \mathrm{~K}, 1 \mathrm{~atm})=22414 \mathrm{~cm}^{3} \mathrm{~mol}^{-1}, V_{\mathrm{m}}(298 \mathrm{~K}, 1 \mathrm{~atm})=$ $24465 \mathrm{~cm}^{3} \mathrm{~mol}^{-1}$, and $V_{\mathrm{m}}(298 \mathrm{~K}, 1$ Torr $)=1.8593 \times 10^{7} \mathrm{~cm}^{3} \mathrm{~mol}^{-1}$.

\subsection{Data acquisition}

The individual data sets were collected from the original publications, i.e. mostly peer-reviewed journal articles, sometimes Ph.D. theses, reports, conference proceedings, or books dealing with photochemistry. The articles originate from journals dealing with atmospheric kinetics and photochemistry or molecular spectroscopy, including also astronomical research. Data were also obtained by personal communication from the authors if the numerical data were not given in the publication. In addition to the original data, for a great number of species, evaluated and recommended cross sections published in the NASA-JPL Reports (Sander et al., 2011, and references cited therein) and by the IUPAC Group (Atkinson et al., 2004, 2006, 2007, 2008) are also presented. Data points in the spectral atlas are always the original data from the cited publication unless noted otherwise in the comments. The data have either been copied from tables or read from figures in those cases where numerical data were not available. More recently, large data sets published as "supplementary information" or "auxiliary material" could be downloaded directly. Many spectral data were downloaded from databases open to the public of several research centres, such as:

- http://www.cfa.harvard.edu/amp/tools.html

- http://www.iup.physik.uni-bremen.de/gruppen/ molspec/index.html

- http://spectrolab.aeronomie.be/index.htm

- http://www.lisa.univ-paris12.fr/GPCOS/SCOOPweb/ SCOOP.html

- http://ams-bmc.nsrrc.org.tw

Finally, unpublished results that are received directly from the authors are also accepted. Indeed, the main aim of the spectral atlas is a collection of measured data and not an evaluation. Inclusion in our spectral atlas does not mean that we endorse the data set or guarantee its quality. Instead, we recommend consulting the overview plots (described below) in order to detect differences between the data sets.

\subsection{Graphical representations}

The graphical representations show the absorption cross sections $\sigma$ vs. wavelength $\lambda$. In contrast to the individual numerical data sets, the plots combine the data from different measurements. Links to the plots are shown on the pages of the individual species. Two kinds of plots are presented, with linear (lin) and logarithmic (log) scaling of the $\sigma$ axis, respectively. The linear plots precisely depict the absorption cross sections near the absorption maxima, while the logarithmic plots emphasize the wings of the absorption curve. For example, small differences in the recently measured cross sections of $\mathrm{ClOOCl}$ at long wavelengths can be seen much better in logarithmic plots. Another example is $\mathrm{BrO}$, as shown in Fig. 1. The names of the plot files are characterized by the notation formula_lin.jpg or formula_log.jpg, e.g. BrO_lin.jpg or BrO_log.jpg.

These plots refer to measurements at room temperature and show the entire UV/VIS wavelength range covered by the various experiments. For plots showing a particular wavelength range, a temperature range, or a publication period, the name of the file contains additional specifications after the formula:

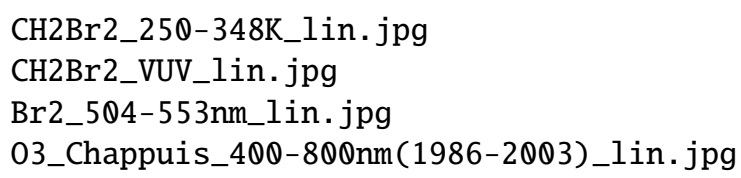

Plots containing more than one species (e.g. H2O, HDO, and D2O) are duplicated and saved for each species, e.g. the following plots are identical:

H2O_and HDO,D20_140-196nm_lin.jpg

HDO_and H2O,D20_140-196nm_lin.jpg

D2O_and H20,HDO_140-196nm_lin.jpg 

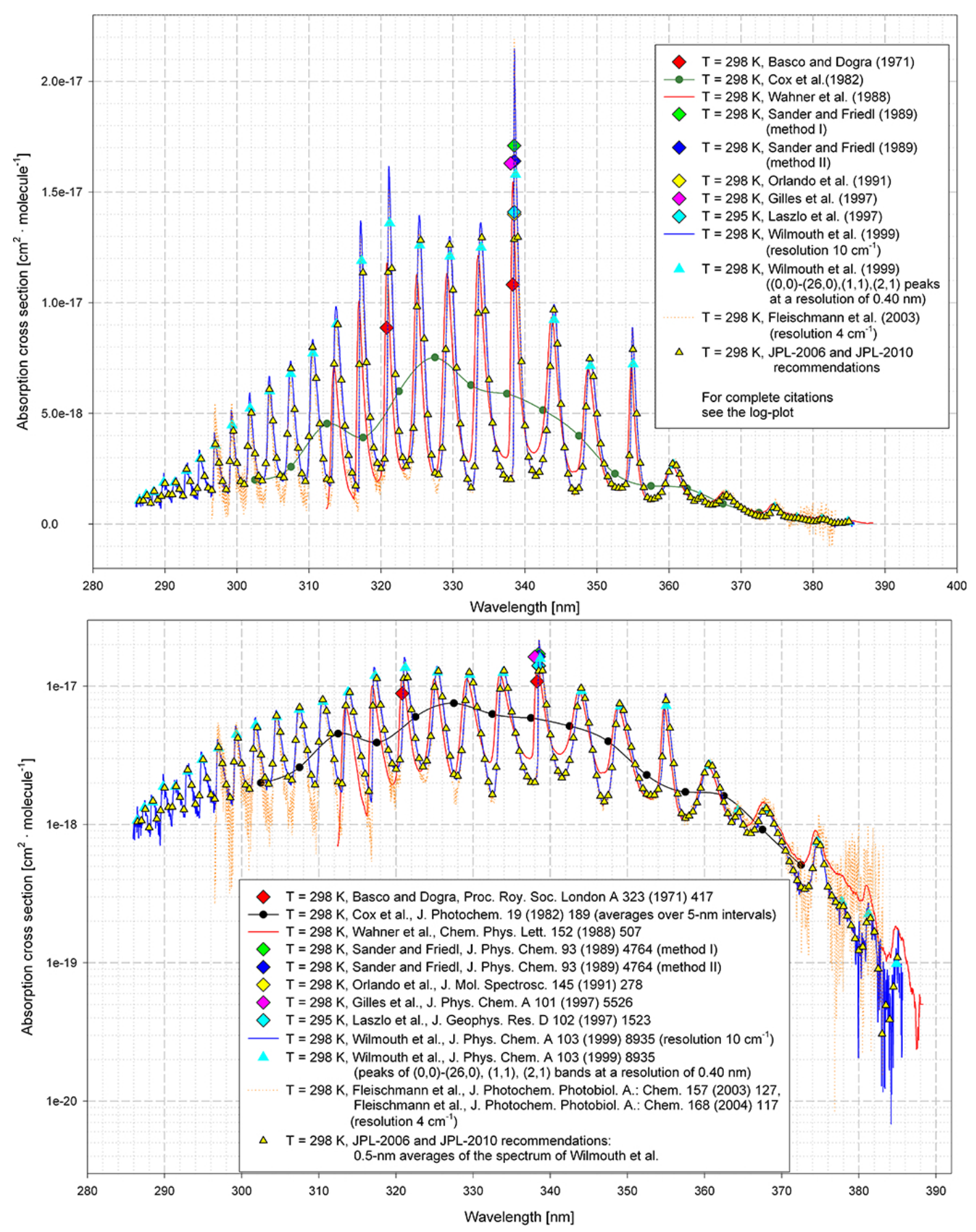

Absorption cross sections of the $\mathrm{A}^{2} \Pi_{3 / 2} \leftarrow \mathrm{X}^{2} \Pi_{3 / 2}$ transition of bromine monoxide $\mathrm{BrO}$ at room temperature

Figure 1. Overview plots of measured $\mathrm{BrO}$ spectra (top = linear, bottom = logarithmic).

\section{Quantum yields}

In many cases, the photolysis of a molecule branches into several product channels, each with different quantum yields at different wavelengths. A classic example is formaldehyde $\left(\mathrm{CH}_{2} \mathrm{O}\right)$, which possesses two product channels:

$$
\begin{aligned}
\mathrm{CH}_{2} \mathrm{O} \stackrel{h v}{\rightarrow} & \mathrm{H}_{2}+\mathrm{CO} \\
& \mathrm{H}+\mathrm{HCO}
\end{aligned}
$$

In the database the dimensionless quantum yields are grouped into the same categories and subcategories as the 


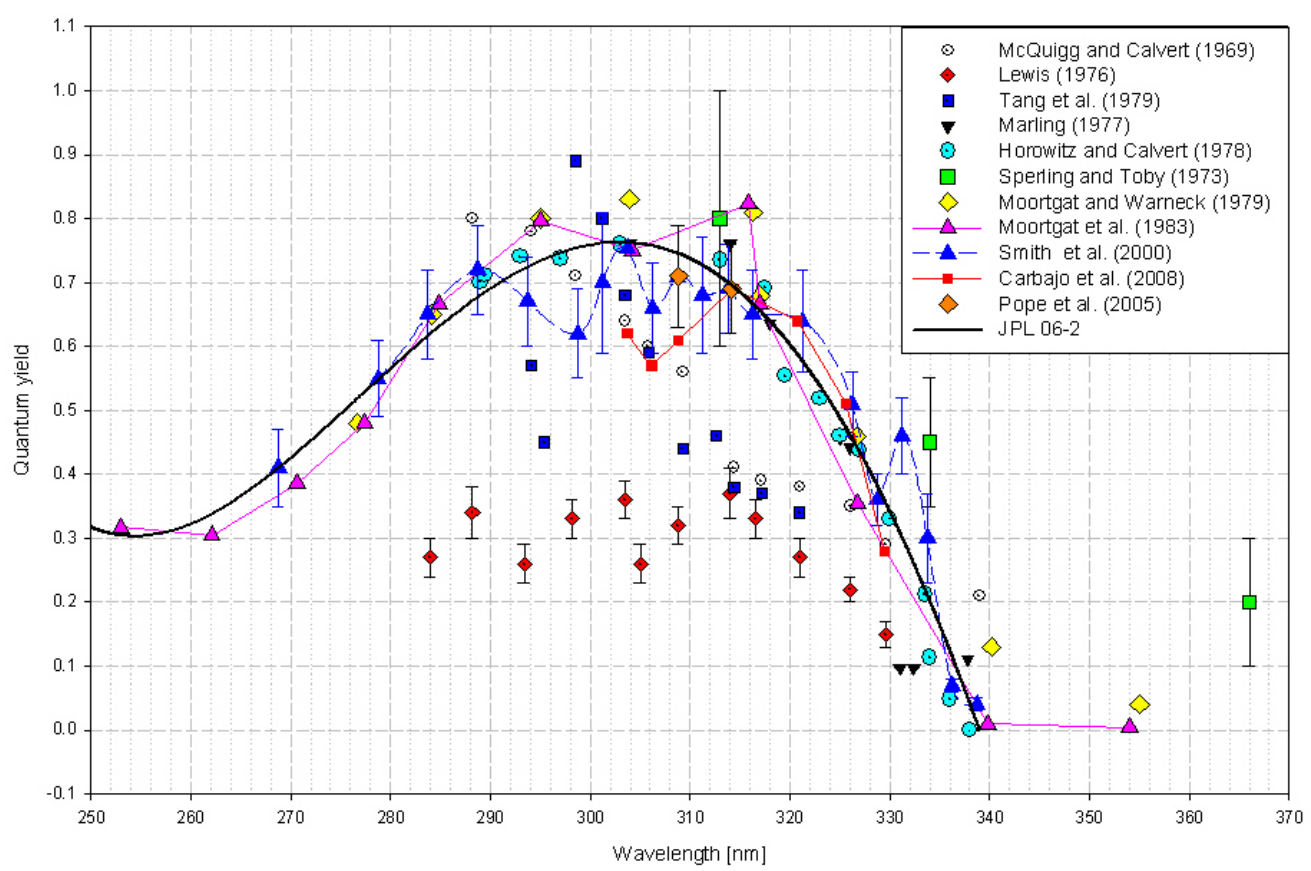

Figure 2. Overview plot of measured quantum yields $\mathrm{CH}_{2} \mathrm{O} \stackrel{h v}{\rightarrow} \mathrm{H}+\mathrm{HCO}$.

Table 5. Example for metadata associated with a quantum yield data set. The corresponding data file is shown in Table 6.

\begin{tabular}{|c|c|}
\hline \multicolumn{2}{|c|}{$\begin{array}{l}\text { Quantum Yields / Organics (carbonyls) / Aldehydes(aliphatic) / CH2O } \rightarrow \mathrm{H}+\mathrm{HCO} / \\
\text { Smith(2002)_298K_268.75-338.75nm }\end{array}$} \\
\hline $\begin{array}{l}\text { DATAFILE: } \\
\text { REACTION: }\end{array}$ & $\begin{array}{l}\mathrm{CH} 2 \mathrm{O}\{\mathrm{H}+\mathrm{HCO}\} \_\mathrm{Smith}(2002) \_298 \mathrm{~K} \_268.75-338.75 \mathrm{~nm} . \mathrm{txt} \\
\text { formaldehyde } \rightarrow \mathrm{H}+\mathrm{HCO} \\
\mathrm{CH} 2 \mathrm{O} \rightarrow \mathrm{H}+\mathrm{HCO}\end{array}$ \\
\hline AUTHOR(YEAR): & Smith(2002) \\
\hline $\mathrm{T}:$ & $298 \mathrm{~K}$ \\
\hline$\lambda:$ & $268.75-338.75 \mathrm{~nm}$ \\
\hline BIBLIOGRAPHY: & $\begin{array}{l}\text { G. D. Smith, L. T. Molina, and M. J. Molina, "Measurement of radical quantum yields from formalde- } \\
\text { hyde photolysis between } 269 \text { and } 339 \text { nm," J. Phys. Chem. A, 106, 1233-1240 (2002) }\end{array}$ \\
\hline COMMENTS: & $\begin{array}{l}\text { The relative quantum yields of the radical products } \mathrm{H} \text { and } \mathrm{HCO} \text { were obtained by conversion to } \mathrm{HO}_{2} \\
\text { using chemical amplification and subsequent detection by CIMS (chemical ionization mass spectrome- } \\
\text { try). The quantum yields were normalized to } 0.753 \text { at } 303.75 \mathrm{~nm} \text { based on the recommendation of JPL } \\
\text { Publ. } 97-4 \text { (DeMore et al. 1997). }\end{array}$ \\
\hline
\end{tabular}

cross sections. Each product channel is treated separately. The names of the quantum yield data files are similar to those for the cross sections but contain the product channels in curly braces directly after the formula:

formula\{products\}_author(year)_T_ $\lambda$.txt

For the example $\mathrm{CH}_{2} \mathrm{O}$, the total quantum yield is also listed and the names are as follows:

$\mathrm{CH} 20\{\mathrm{H} 2+\mathrm{CO}\} \_$author(year)_T_ $\lambda$.txt

$\mathrm{CH} 20\{\mathrm{H}+\mathrm{HCO}\} \_$author(year)_T_ $\lambda . \mathrm{txt}$

CH20\{total\}_author(year)_T_ $\lambda . t x t$

An example for quantum yield metadata associated with the data set by Smith et al. (2002) is given in Table 5, together with the corresponding data file in Table 6 . The quantum yields are stored as plain ASCII files within two columns: one for the wavelength, and the other for the quantum yield, respectively. A third column occasionally indicates the error limits of the quantum yields. Figure 2 represents the overview plot of the quantum yields for the product channel $\mathrm{CH}_{2} \mathrm{O} \stackrel{h v}{\rightarrow} \mathrm{H}+\mathrm{HCO}$.

It is worthwhile to mention that the ozone category covers nearly 30 quantum yield studies for a single molecule, whereas other categories, such as nitrogen oxides and halogen oxides, report many data sets for a variety of molecules, such as $\mathrm{NO}_{2}, \mathrm{NO}_{3}, \mathrm{~N}_{2} \mathrm{O}_{5}$ and the chlorine oxides $\mathrm{Cl}_{2} \mathrm{O}$, $\mathrm{ClOOCl}$ and $\mathrm{OClO}$, respectively. 
Table 6. As an example for a quantum yield data file, the contents of CH2O $\{\mathrm{H}+\mathrm{HCO}\} \_S m i t h(2002) \_298 \mathrm{~K} \_268.75-338.75 \mathrm{~nm} . \mathrm{txt}$ is shown here. It belongs to the data set from Smith et al. (2002) shown in Table 5.

\begin{tabular}{ll}
\hline 268.75 & $0.41 \pm 0.06$ \\
278.75 & $0.55 \pm 0.06$ \\
283.75 & $0.65 \pm 0.07$ \\
288.75 & $0.72 \pm 0.07$ \\
293.75 & $0.67 \pm 0.07$ \\
298.75 & $0.62 \pm 0.07$ \\
301.75 & $0.70 \pm 0.11$ \\
303.75 & 0.753 \\
306.25 & $0.66 \pm 0.07$ \\
308.75 & $0.71 \pm 0.08$ \\
311.25 & $0.68 \pm 0.09$ \\
313.75 & $0.69 \pm 0.07$ \\
316.25 & $0.65 \pm 0.07$ \\
321.25 & $0.64 \pm 0.08$ \\
326.25 & $0.51 \pm 0.05$ \\
328.75 & $0.36 \pm 0.04$ \\
331.25 & $0.46 \pm 0.06$ \\
333.75 & $0.30 \pm 0.07$ \\
336.25 & $0.07 \pm 0.01$ \\
338.75 & $0.04 \pm 0.01$ \\
\hline
\end{tabular}

\section{Technical implementation of the new version of the spectral atlas}

Recently, the database and the Web pages have been completely redesigned and restructured.

\subsection{The database}

All absorption cross section and quantum yield data sets are stored as plain ASCII files. The metadata (formula and name, CAS registry number, InChIKey, category, reference, temperature, wavelength range, comments) are stored as tables in a PostgreSQL database system ${ }^{3}$, as shown in Fig. 3. Oneto-many relations are implemented as foreign keys. Access to the database is implemented via the Django Web framework $^{4}$, written in the Python programming language.

\subsection{The Web pages}

To browse the MPI-Mainz UV/VIS Spectral Atlas, clicking the links to Cross Sections and Quantum Yields in the left column will show molecular categories and subcategories. Inside these (sub)categories are the species. The pages for the species contain links to the graphical representations and the individual measurements. Four search options are provided in the right column:

\footnotetext{
${ }^{3}$ http://www.postgresql.org/

${ }^{4}$ https://www.djangoproject.com/
}

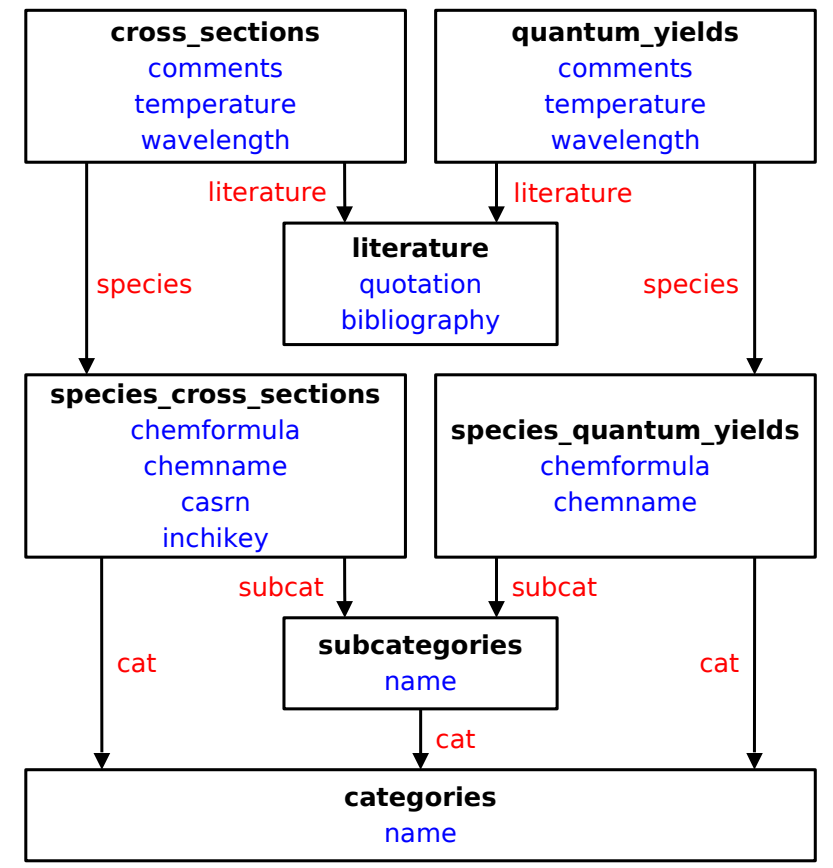

Figure 3. Structure of the PostgreSQL database. Black = table names; blue = table columns; and red $=$ foreign keys pointing to other tables.

1. Species Search: find the search string in the species' name or formula.

2. Identifier Search: find the search string in the species' CAS registry number or InChIKey.

3. Reference Search: find the search string somewhere in the reference (author, title, journal) and return all data sets from that article.

4. Full Text Search: search the species, the references, and also the comments.

All searches are case-insensitive.

\section{Summary and outlook}

We have presented the MPI-Mainz UV/VIS Spectral Atlas, which now appears on the Web with a new look, a clear structure and improved search functions. To the best of our knowledge, it is the most comprehensive collection of UV/VIS absorption spectra and an advanced collection of quantum yield data sets. Here at the Max-Planck Institute for Chemistry, we will continue to maintain, update and extend the various sections of the Atlas. 
Acknowledgements. We would like to thank T. Wagner for hosting the spectral atlas on the Web server of the satellite group. K. Egenolf and E. Uherek helped us to retrieve the database from the previous, now obsolete, Web server. A. Kunert provided most of the CAS registry numbers. Last but not least, we are looking forward to receiving comments and additional data sets from the scientific community to further expand our collection.

Author contributions. G. K. Moortgat has been collecting and contributing spectra to this database since the 1990s. H. KellerRudek has been adding data, creating plots, updating, and maintaining the spectral atlas on the previous Web server from 1998 until 2012. R. Sörensen and R. Sander converted the database to PostgreSQL and implemented the new Web pages. Current contact persons are H. Keller-Rudek for the cross sections, G. K. Moortgat for the quantum yields, and R. Sörensen and R. Sander for the database and the Web interface.

Edited by: D. Carlson

\section{References}

Atkinson, R., Baulch, D. L., Cox, R. A., Crowley, J. N., Hampson, R. F., Hynes, R. G., Jenkin, M. E., Rossi, M. J., and Troe, J.: Evaluated kinetic and photochemical data for atmospheric chemistry: Volume $\mathrm{I}-$ gas phase reactions of $\mathrm{O}_{\mathrm{x}}, \mathrm{HO}_{\mathrm{x}}, \mathrm{NO}_{\mathrm{x}}$ and $\mathrm{SO}_{\mathrm{x}}$ species, Atmos. Chem. Phys., 4, 1461-1738, doi:10.5194/acp-41461-2004, 2004.

Atkinson, R., Baulch, D. L., Cox, R. A., Crowley, J. N., Hampson, R. F., Hynes, R. G., Jenkin, M. E., Rossi, M. J., Troe, J., and IUPAC Subcommittee: Evaluated kinetic and photochemical data for atmospheric chemistry: Volume II - gas phase reactions of organic species, Atmos. Chem. Phys., 6, 3625-4055, doi:10.5194/acp-6-3625-2006, 2006.

Atkinson, R., Baulch, D. L., Cox, R. A., Crowley, J. N., Hampson, R. F., Hynes, R. G., Jenkin, M. E., Rossi, M. J., and Troe, J.: Evaluated kinetic and photochemical data for atmospheric chemistry: Volume III - gas phase reactions of inorganic halogens, Atmos. Chem. Phys., 7, 981-1191, doi:10.5194/acp-7-981-2007, 2007.

Atkinson, R., Baulch, D. L., Cox, R. A., Crowley, J. N., Hampson, R. F., Hynes, R. G., Jenkin, M. E., Rossi, M. J., Troe, J., and Wallington, T. J.: Evaluated kinetic and photochemical data for atmospheric chemistry: Volume IV - gas phase reactions of organic halogen species, Atmos. Chem. Phys., 8, 4141-4496, doi:10.5194/acp-8-4141-2008, 2008.

Cox, R. A., Sheppard, D. W., and Stevens, M. P.: Absorption coefficients and kinetics of the $\mathrm{BrO}$ radical using molecular modulation, J. Photochem., 19, 189-207, 1982.

Es-sebbar, E., Benilan, Y., and Farooq, A.: Temperature-dependent absorption cross-section measurements of 1-butene $\left(1-\mathrm{C}_{4} \mathrm{H}_{8}\right)$ in VUV and IR, J. Quant. Spectrosc. Radiat. Transfer, 115, 1-12, 2013.
Nölle, A., Pätzold, F., Pätzold, S., Meller, R., Moortgat, G. K., Röth, E.-P., Ruhnke, R., and Keller-Rudek, H.: UV/VIS Spectra of Atmospheric Constituents, Version 1, Tech. rep., ATMOS User Center at Deutsches Fernerkundungsdatenzentrum (DFD), 1998.

Ny, T.-Z. and Choong, S.-P.: L'absorption de la lumière par l'ozone entre 3050 et $3400 \AA$ A, C. R. Hebd. Séances Acad. Sci., 195, 309$311,1932$.

Ny, T.-Z. and Choong, S.-P.: L'absorption de la lumière par l'ozone entre 3050 et $2150 \AA$ A, C. R. Hebd. Séances Acad. Sci., 196, 916 918, 1933a.

Ny, T.-Z. and Choong, S.-P.: Sur l'absorption ultraviolette de l'ozone, Chin. J. Phys., 1, 38-54, 1933b.

Röth, E.-P., Ruhnke, R., Moortgat, G., Meller, R., and Schneider, W.: UV/VIS-Absorption Cross Sections and Quantum Yields for Use in Photochemistry and Atmospheric Modeling, Part 1: Inorganic Substances, Tech. Rep. jül-3340, Institut für Chemie und Dynamik der Geosphäre 1: Stratosphärische Chemie, Jülich, Germany, 1997a.

Röth, E.-P., Ruhnke, R., Moortgat, G., Meller, R., and Schneider, W.: UV/VIS-Absorption Cross Sections and Quantum Yields for Use in Photochemistry and Atmospheric Modeling, Part 2: Organic Substances, Tech. Rep. jül-3341, Institut für Chemie und Dynamik der Geosphäre 1: Stratosphärische Chemie, Jülich, Germany, 1997b.

Sander, S. P., Abbatt, J., Barker, J. R., Burkholder, J. B., Friedl, R. R., Golden, D. M., Huie, R. E., Kolb, C. E., Kurylo, M. J., Moortgat, G. K., Orkin, V. L., and Wine, P. H.: Chemical Kinetics and Photochemical Data for Use in Atmospheric Studies, Evaluation No. 17, JPL Publication 10-6, Jet Propulsion Laboratory, Pasadena, http://jpldataeval.jpl.nasa.gov, 2011.

Smialek, M. A., Hubin-Franskin, M.-J., Delwiche, J., Duflot, D., Mason, N. J., Vrønning-Hoffmann, S., de Souza, G. G. B., Ferreira Rodrigues, A. M., Rodrigues, F. N., and Limão-Vieira, P.: Limonene: electronic state spectroscopy by high-resolution vacuum ultraviolet photoabsorption, electron scattering, $\mathrm{He}(\mathrm{I})$ photoelectron spectroscopy and ab initio calculations, Phys. Chem. Chem. Phys., 14, 2056-2064, 2012.

Smith, G. D., Molina, L. T., and Molina, M. J.: Measurement of radical quantum yields from formaldehyde photolysis between 269 and 339 nm, J. Phys. Chem. A, 106, 1233-1240, 2002.

Urey, H. C., Dawsey, L. H., and Rice, F. O.: The absorption spectrum and decomposition of hydrogen peroxide by light, J. Am. Chem. Soc., 51, 1371-1383, 1929.

Vassy, A. and Vassy, E.: Effect of temperature on the absorption spectrum of ozone: Chappuis bands, J. Chem. Phys., 16, 1163 1164, 1948.

Vigroux, E.: Absorption de l'ozone dans la région des bandes de Huggins. Influence de la température, C. R. Hebd. Séances Acad. Sci., 230, 2170-2172, 1950.

von Halban, H. and Siedentopf, K.: Die Lichtabsorption des Chlors, Z. Elektrochem., 28, 496-499, 1922. 